\title{
Electrochemical Investigation of P-Tert-Butylcalix[6]Arene Modified Gold Electrode for Ionic Detection
}

\author{
H. Sakly' ${ }^{1}$, H. Ben Ouada ${ }^{1}$, N. Jaffrezic Renault ${ }^{2}$ \\ ${ }^{1}$ University Monastir, Laboratoire des Interfaces et Matériaux Avancés, Faculté des Sciences de Monastir, \\ Monastir, Tunisie \\ ${ }^{2}$ University Lyon, Institut des Sciences Analytiques, CNRS/ENS/UCBL UMR 5280, Villeurbanne, France \\ Email: hasnasakly@yahoo.fr
}

Received 20 March 2014; revised 3 May 2014; accepted 18 May 2014

Copyright @ 2014 by authors and Scientific Research Publishing Inc.

This work is licensed under the Creative Commons Attribution International License (CC BY).

http://creativecommons.org/licenses/by/4.0/

c) (7) Open Access

\begin{abstract}
The aim of this work was to study the electrochemical behavior of gold electrode which was modified with p-tert-butylcalix[6]arene membrane and this in the presence of different nickel ions based concentrations in order to form a nickel electrochemical sensor. For that, impedance-spectroscopy characteristics have been investigated. The obtained results were then modeled by appropriate equivalent circuit aiming at elucidating the electrical properties of the modified gold transducer. A correlation between the present impedimetric results and previous potentiometric ones was achieved traducing then a fast ionic transfer.
\end{abstract}

\section{Keywords}

P-Tert-Butylcalix[6]Arene, Gold Electrode, Impedimetric Sensor, Electrochemical Impedance Spectroscopy

\section{Introduction}

An intensive evolution in the field of the development in the determination of chemical species in solution has been observed during the last two decades. This tendency is especially noticeable in environmental monitoring and industrial process control, which requires continuous and on-site measurements [1] [2]. In order to satisfy the need of chemical, industrial and environmental analyses, the interest in chemical sensors has increased sharply [3].

An electrochemical sensor is based on two essential components: a transducer and a sensing membrane. 
Among various transducers, electrochemical transduction strategies are based on detection of changes in electron transfer caused by the chemical reactions or specific interactions between recognition elements and analytes. In particular, this detection is accomplished by using amperometric, potentiometric, conductometric (at constant voltage), or impedimetric (at alternating voltage) devices [4]-[7].

Owing to their recognition properties, calixarenes [8]-[10] with their natural basket-shaped cavities have already found application in the design of chemical sensors using an electrochemical transduction [11]-[13].

Their cavitary structure, allows them to form complex inclusions with various chemical species. The selectivity of calixarenes depends on the nature of the polar or unpolar functional groups on the edge of the cavity but also on the size of the cavity.

The direct result of this potential of calixarenes was using them for creating electrochemical sensors. The selective recognition of some cations is undoubtedly the most developed use of calixarenes. There are commercial selective electrodes which determine the sodium level in blood but the calixarenes also form complexes with potassium, cadmium, lanthanide, actinide, silver, lead, calcium, copper, zinc, mercury, being used for detecting the level of air or water pollution, in toxicology or clinical analysis [14]-[16].

Besides its use as transduction principle in the field of chemical sensors [17], the electrochemical impedance spectroscopy technique has become of compulsory use to describe and investigate kinetics and electrochemical interfaces of any electrode system [18]-[20]. This technique allows to characterize both resistive and capacitive proprieties of materials based on perturbation of a systems at equilibrium by a sinusoidal excitation signal of small amplitude, the measurement are carried out at different frequencies analyses of the system response contains informations concerning the interface [21] [22].

Starting from the fact that nickel interact selectively with p-tert-butylcalix[6]arene [23], this study intends to investigate the electrochemical behavior of p-tert-butylcalix[6]arene modified gold electrode using the impedimetric characterization. A correlation between the present results and the potentiometric ones previously reported is proposed.

\section{Materials and Methods}

\subsection{Materials}

In this study, gold electrodes were used as transducer and p-tert-butylcalix[6]arene (C6) membrane as ionophore.

Calixarenes are macrocycles formed by cyclooligomerization of phenol and formaldehyde. In such molecules, the lower rim is already functionalized with hydroxyl groups, and the upper rim bears alkyl groups: the tertbutyl. Now they can be synthesized in a rich variety of ring sizes and substitution patterns. Their ability to complex cations, anions, and neutral molecules has made them a standard among supramolecular host molecules [8].

Calixarene solubility in many organic solvents, such as chloroform, enables their deposition on gold substrates using the spin-coating method. Therefore, all coatings were performed with a spinning velocity of 2500 rpm and a spinning time of $60 \mathrm{~s}$.

The active surface (S) of the gold working electrode was about $0.3 \mathrm{~cm}^{2}$. Gold electrodes were cleaned for about $5 \mathrm{~min}$ in a sulfochromic mixture [24]. After this treatment the electrodes were rinsed with ultra pure water in order to remove any impurities. Calixarene spin coated gold electrodes were then conditioned in a $10^{-3} \mathrm{M}$ solution of the nickel ion for $15 \mathrm{~h}$ before measuring.

As electrolyte, ammonium acetate $\left(\mathrm{CH}_{3} \mathrm{COO}^{-} \mathrm{NH}_{4}^{+}\right)$was used in order to avoid any interference from the electrolyte ions in the ionic equilibrium at the sensitive interface and thus any interference with the ions to be analyzed. As the calixarene cage is hydrophobic and the $\mathrm{NH}_{4}^{+}$ion is hydrophilic, the latter cannot enter in the cavity of the calixarene. Moreover, the electrolyte $(\mathrm{pH} 7)$ allows preservation of the intramolecular hydrogen bonds between the hydroxyl groups which are responsible for the calixarene conformation [25].

\subsection{Methods}

The electrochemical experimental measurements within this study were performed using computer controlled electrochemical system (Voltalab 40 impedance analyzer from Radiometer Analytical SA, Villeurbanne, France). All the experiments were performed with a $10 \mathrm{mV}$ signal for the amplitude modulation and a frequency range of $100 \mathrm{mHz}$ - $100 \mathrm{KHz}$, the impedance data were calculated with a computer program. 
These measurements were performed at room temperature $23^{\circ} \mathrm{C}-25^{\circ} \mathrm{C}$.

The analysis of the impedance data was done by using the Z-View2 software, and then the equivalent electric circuits were obtained. The parameters of the equivalent circuit were optimised to ensure the best fit of the experimental data over the entire frequency range [26].

For the electrochemical sensor characterization, the C6 modified gold electrode (the working electrode) has been mounted into a plexiglas measuring electrochemical cell in contact with the analyte solution: the ammonium acetate $\left(\mathrm{CH} 3 \mathrm{COO}^{-} \mathrm{NH}_{4}^{+}\right)$. A saturated calomel electrode (SCE) was used as a reference electrode and a platinum grid as a counter electrode. The latter presented a large dimension in order to neglect counter electrode impedance in Randles electric circuit [27].

Freshly prepared nickel standards from $10^{-6} \mathrm{M}$ to $10^{-1} \mathrm{M}$ were used in order to determine the electrochemical behaviour of the modified transducer.

Water contact-angle measurements have been performed before and after the functionalization process of the gold electrode with a model contact angle instrument (Digidrop) from GBX (Romans, France) [28]. Every reported contact angle measurement represents an average value of at least four separated drops on different areas of the given wafer. The size and volume of the drops were kept constant since it is known that variations in the volume of the drops can lead to inconsistent contact angle measurements [29].

\section{Results and Discussion}

\subsection{Contact Angle Measurements}

In order to check the effectiveness of the functionalization process, contact angle measurements, obtained with water as test liquid, have been carried out for the modified gold electrode. The wetting properties have been compared before and after the functionalization process (Table 1).

We notice that the contact angle increases after functionalization proving that the C6 molecules have been well deposited on the gold electrode surface.

\subsection{Electrochemical Characterization of the Calixarene Modified Gold Electrode}

Sensing properties and selectivities of C6 towards nickel were largely investigated in previous paper [3]. Both complementary character of the macrocyclic cavity (shape, size, number of bonding sites) and the cationic target determine the structure of the complex formed.

In the first time, experimental conditions were optimized in terms of voltage and frequency; for a polarisation $-0.9 \mathrm{~V} / \mathrm{SCE}$ and a frequency range of $100 \mathrm{mHz}$ to $100 \mathrm{kHz}$.

The impedance measurements realized before and after the membrane deposition presented in the complex plane are shown in Figure 1.

We can see that at high frequencies the impedance is not modified however, at low frequency, the impedance of the electrochemical system decreases; this renders possible the observation of the ion exchange sensitivity influence especially at low frequency.

A comparison of complex impedance plots of nacked gold electrode and C6 covered gold electrode shows the effect of the absorbed C6 layer on the ac response. For a C6 covered electrode, $\mathrm{R}_{\mathrm{ct}}$, which is the diameter of the semicircle at high frequency, is clearly greater than $\mathrm{R}_{\mathrm{ct}}$ due to an inhibition of C6/gold electrode to electron transfer.

In the presence of nickel ions (Figure 2), we can notice that at high frequencies the impedance of C6 modified gold electrode is not modified. However, at low frequency, the impedance of the electrochemical system decreases significantly with increasing concentrations of $\mathrm{Ni}^{2+}$.

In the Nyquist diagram (Figure 3), the approximate form is a semi-circle, which indicates that the electrochemical system can be represented by a parallel circuit of resistive and capacitive components. These components correspond to the membrane resistance $\left(R_{m}\right)$ (significant part of the sensor) and capacitance $\left(C_{m}\right)$. It seems that the C6 film creates a barrier to ion transfer, preventing thus their access to the gold electrode.

Such electrical behaviors of the C6 based impedimetric sensor was interpreted by computational analysis using the Zview program [26], and expressed by the following equivalent circuit: $\left[R_{1}\left(C E_{1} R_{2}\right)\right]$ where $R_{1}$ stands for the aqueous solution resistance, $\mathrm{R}_{2}$ for the film resistance and $\mathrm{CPE}_{1}$ for constant phase elements [30]-[32]. The latter is a non-ideal capacitance that takes into account the interfacial irregularities (porosity, roughness, and 
Table 1. Contact angle before and after functionnalization process of gold electrode.

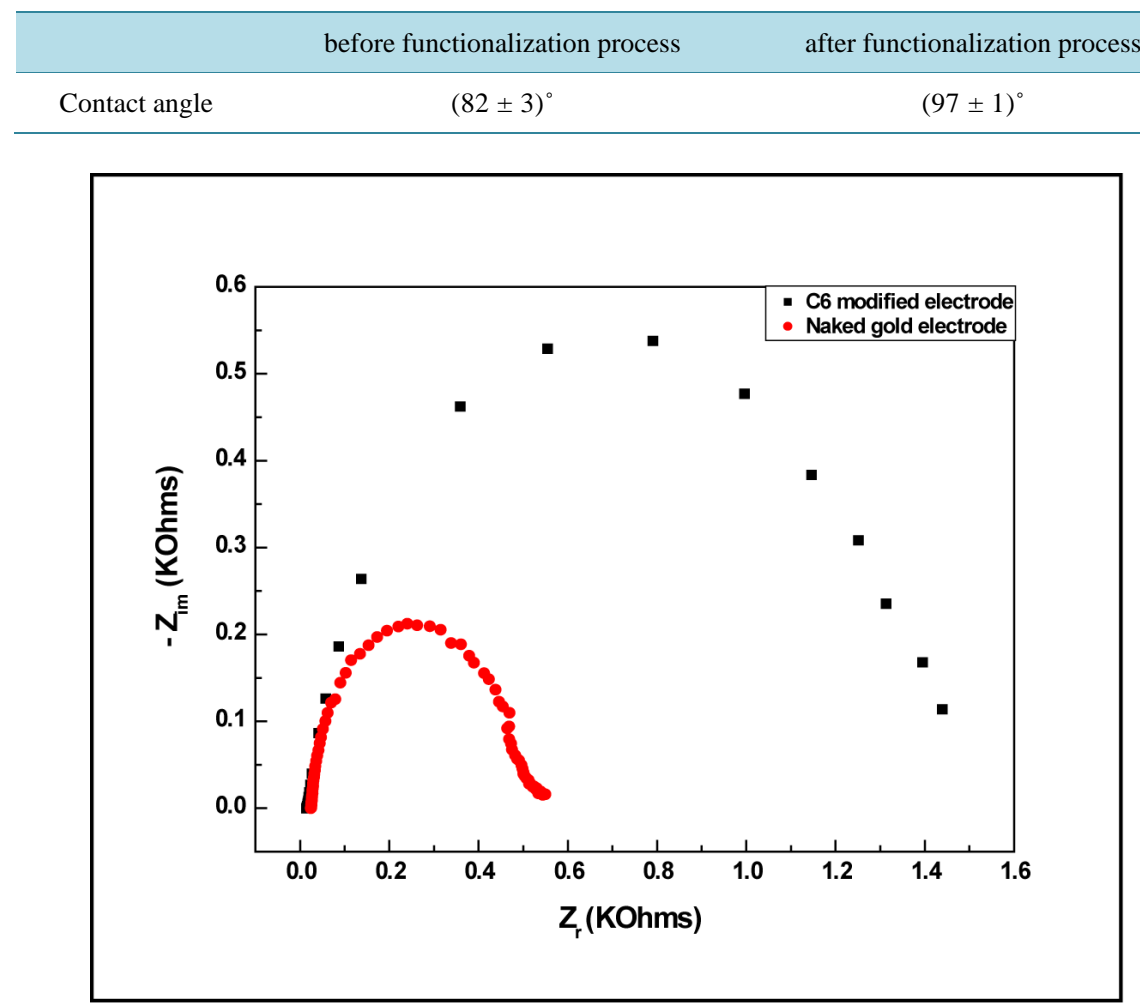

Figure 1. Nyquist plots for naked gold electrode and C6 modified gold electrode.

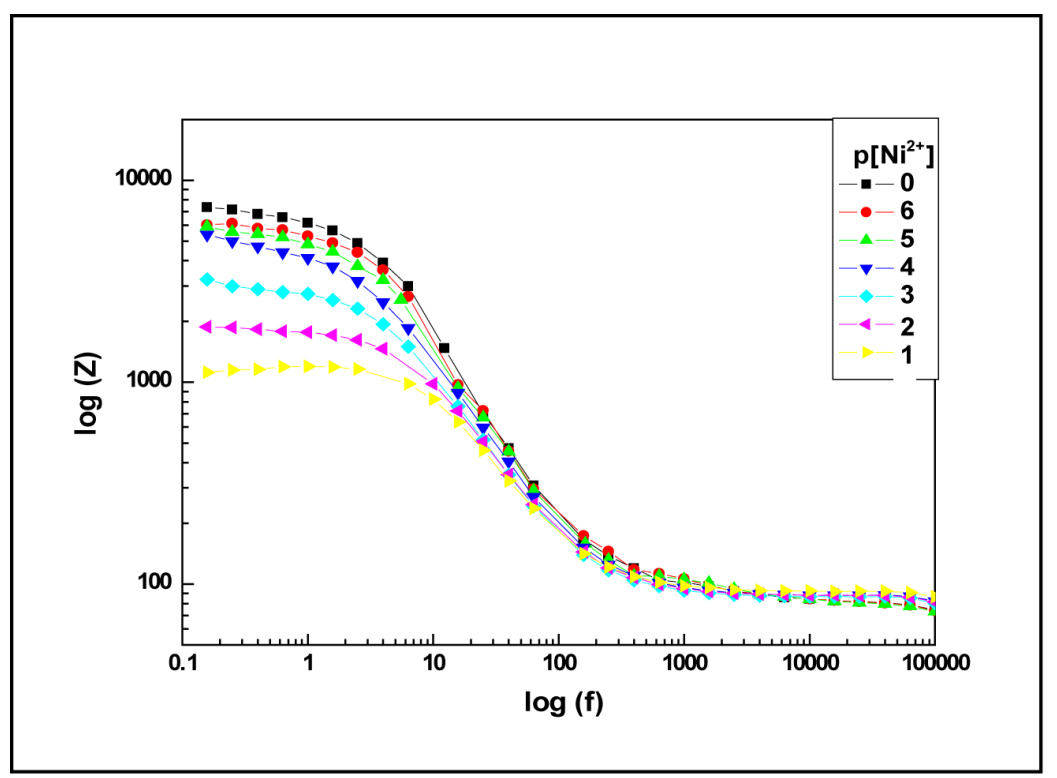

Figure 2. Evolution of Bode spectra of C6 modified gold electrode vs. concentrations of $\mathrm{Ni}(\mathrm{II})$.

geometry). Its impedance is defined as $\mathrm{Z}_{\mathrm{CPE}}=-1 /(\mathrm{j} \omega \mathrm{Q})^{\mathrm{n}}$. The pure resistances, Warburg terms, capacitances and inductances corresponding to $\mathrm{n}=0,0.5,1,-1$, respectively.

In our case, according to the result of the fit $n$ is close to 1 then $\mathrm{CPE}_{1}$ is a pure specific capacitance attributed to the calixarene film itself. 


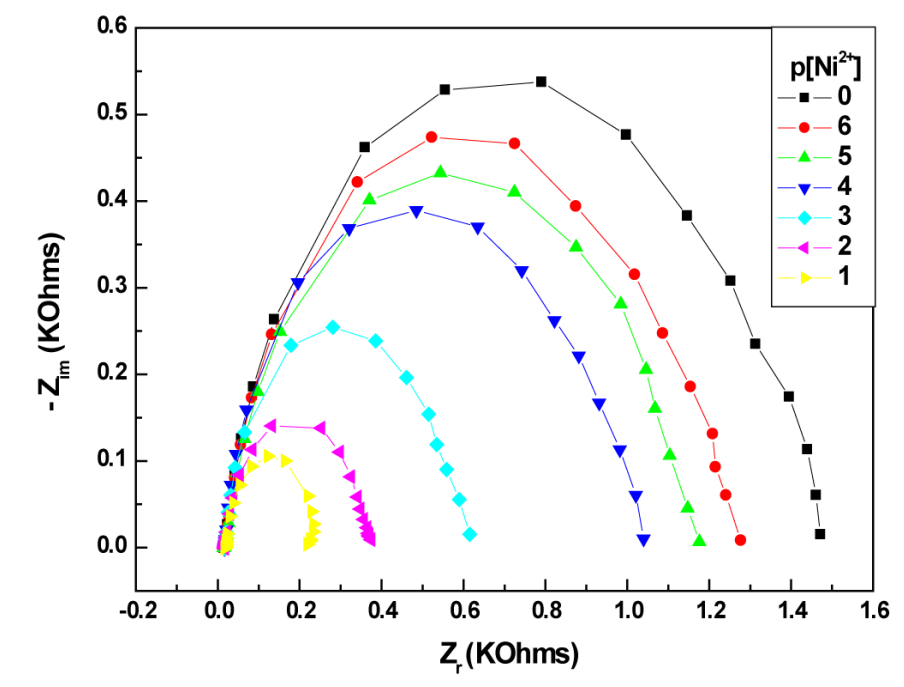

Figure 3. Evolutions of Nyquist spectra of C6 modified gold electrode vs. concentrations of $\mathrm{Ni}(\mathrm{II})$.

It is important noteworthy that the semi-circle decreases when increasing concentrations of nickel (in the range from $10^{-6} \mathrm{M}$ to $10^{-1} \mathrm{M}$ ). This sequential change of the impedance with the cologarithm of nickel concentration $\left(\mathrm{p}\left[\mathrm{Ni}^{2+}\right]\right)$ indicates that the modified gold electrode is $\mathrm{p}\left[\mathrm{Ni}^{2+}\right]$ sensitive.

When $\mathrm{p}\left[\mathrm{Ni}^{2+}\right]$ increases, the concentration of $\mathrm{Ni}^{2+}$ at the electrode decreases and the thickness of the electrical double layer increases due to the lower charged ion concentration, resulting in the decrease of the double layer capacitance.

To obtain the calibration curve of the $\mathrm{Ni}^{2+}$ sensor, we have plotted the variation of $\mathrm{R}_{\mathrm{m}}$ versus $\mathrm{Ni}^{2+}$ concentration in a semi-logarithmic scale (Figure 4). $\mathrm{R}_{\mathrm{m}}$ corresponds to the membrane resistance obtained from the fit at different concentrations of the detected ion.

By linear curve fitting, the detection sensitivity is determined by the slop of the line to be $-1116 \mathrm{KOhm}$ per decade concentration of nickel.

From the obtained data, it is seen that the impedimetric calixarene sensor presents a linear dependence of the sensor signal with a detection limit of about $10^{-6} \mathrm{M}$.

\subsection{Comparison of Proposed Sensor with Other Reported Sensors}

At this stage, a comparative study was established using previous results obtained with other transducers such as Electrolyte/Isolant/Semiconductor (EIS) heterostructures in which the semiconductor has a flat $\left(\mathrm{Si} / \mathrm{SiO}_{2} / \mathrm{C} 6 /\right.$ Electrolyte) or a porous structure ( $\mathrm{Si} / \mathrm{P}_{\mathrm{SiO}} / \mathrm{C} 6 /$ Electrolyte) with respect to some characteristics such as low detection limit and linear range. The mentioned comparisons are shown in Table 2.

As it is clear, by using gold electrode as transducer the detection limit is larger than those obtained with flat or porous heterostructures.

Besides, the closer Nernstian responses (with respect to the Nernst law) [33] that were obtained with the previously studied potentiometric sensors could be correlated with the present impedimetric sensor. Indeed, the appearance of a single semi circle in impedance plots traduces the Nernstian response. This phenomenon is interpreted by a fast ion exchange that occurs at the p-tert-butylcalix[6]arene/electrolyte interface, correlated to the high conductivity of the film.

\section{Conclusions}

Electrochemical characterizations of a C6 modified gold electrode have been reported in this work. Impedance 


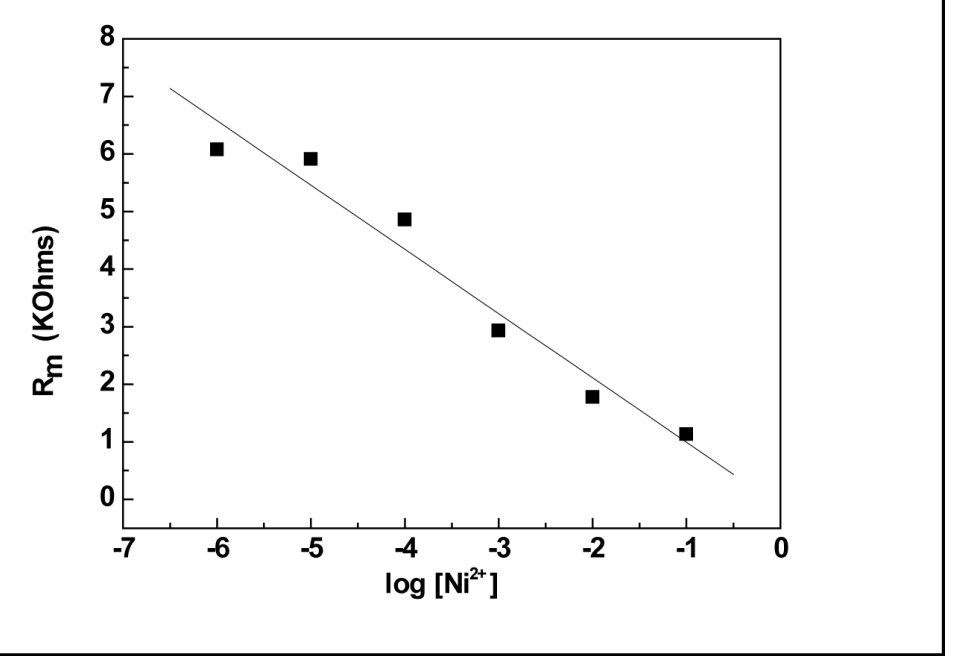

Figure 4. Variation of the p-tert-butylcalix[6]arene membrane resistance against the nickel concentration.

Table 2. Comparison of proposed sensor with some recently reported works.

\begin{tabular}{|c|c|c|c|}
\hline & This work: Gold/C6/Electrolyte & $\mathrm{Si} / \mathrm{SiO}_{2} / \mathrm{C6} /$ Electrolyte & $\mathrm{Si} \mathrm{P/SiO} /$ C6/Electrolyte \\
\hline Detection method & Impedimetric & Potentiometric & Potentiometric \\
\hline Detected substance & $\mathrm{Ni}^{2+}$ & $\mathrm{Ni}^{2+}$ & $\mathrm{Ni}^{2+}$ \\
\hline Sensibility (mV/p $\left.\left[\mathrm{Ni}^{2+}\right]\right)$ & $-1116 \mathrm{ul} / \mathrm{p}\left[\mathrm{Ni}^{2+}\right]$ & 24 & 28 \\
\hline Linear range (M) & $10^{-6}-10^{-1}$ & $10^{-3}-10^{-1}$ & $10^{-3}-10^{-1}$ \\
\hline Detection limit (M) & $10^{-6}$ & $10^{-3}$ & $10^{-3}$ \\
\hline Reference & - & [23] & [34] \\
\hline
\end{tabular}

spectroscopy was used to characterize the proposed structure.

It was shown that by using gold electrode as transducer the detection limit is larger than those obtained with flat or porous heterostructures.

On the other hand, and by combining our impedimetric results with potentiometric ones that were previously reported, a good correlation is obtained. The nernstian response is correlated with the appearance of a single semi circle in Nyquist plots. This phenomenon traduces thus a fast ionic exchange taking place at the calyx[6] arene/electrolyte interface.

\section{References}

[1] Cali, C., Fiox, D., Taillades, G., et al. (2002) Copper (II) Selective Electrode Based on Chalcogenide Materials: Study of the Membrane/Solution Interface with Electrochemical Impedance Spectroscopy and X-Ray Photoelectron Spectroscopy. Materials Science and Engineering C, 21, 3-8. http://dx.doi.org/10.1016/S0928-4931(02)00053-X

[2] Legin, A.V., Bychkov, E.A. and Vlasov, Y.G. (1995) Analytical Applications of Chalcogenide Glass Chemical Sensors in Environmental Monitoring and Process Control. Sensors and Actuators B: Chemical, 24, 309-311. http://dx.doi.org/10.1016/0925-4005(95)85067-8

[3] Barhoumi, H., Maaref, A., Mlika, R., et al. (2005) EIS Field Effect Structures Functionalized by p-tert-butylcalix[6] arene for $\mathrm{Ni}^{2+}$ detection. Materials Science and Engineering C, 25, 61-66. http://dx.doi.org/10.1016/j.msec.2004.07.002

[4] Reymond, F., Fermín, D., Lee, H.J. and Girault, H. (2000) Electrochemistry at Liquid:Liquid Interfaces: Methodology and Potential Applications. Electrochimica Acta, 45, 2647-2662. http://dx.doi.org/10.1016/S0013-4686(00)00343-1

[5] Shöening, M.J. (2005) Playing around with Field-Effect Sensors on the Basis of EIS Structures. LAPS and ISFETs Sensors, 5, 126-138. 
[6] Bard, A.J. and Faulkner, L.R. (2001) Electrochemical Methods. J. Willey \& Sons, New York.

[7] Maupas, H., Saby, C., Martelet, C., et al. (1996) Impedance Analysis of Silicon/Silicon Dioxide Heterostructures Grafted with Antibodies: An Approach for Immunosensor Development. Journal of Electroanalytical Chemistry, 406, 53-58. http://dx.doi.org/10.1016/0022-0728(95)04443-4

[8] Gutsche, C.D. (1989) Calixarenes. Royal Society of Chemistry, Cambridge.

[9] Diamond, D. and Nolan, K. (2001) Calixarenes: Designer Ligands for Chemical Sensors. Analytical Chemistry, 73, 22A-29A.

[10] Ludwing, R. and Thi Kim Dzung, N. (2002) Calixarene-Based Molecules for Cation Recognition. Sensors, 2, 397-416. http://dx.doi.org/10.3390/s21000397

[11] Diamond, D., Svehla, G., Seward, E.M. and McKervey, M.A. (1988) A Sodium Ion-Selective Electrode Based on p-t-butylcalix[4]aryl Acetate as the Ionophore. Analytica Chimica Acta, 204, 223-231. http://dx.doi.org/10.1016/S0003-2670(00)86361-8

[12] Diamond, D. and McKervey, M.A. (1996) Calixarene-Based Sensing Agents. Chemical Society Reviews, 25, 15-24. http://dx.doi.org/10.1039/cs9962500015

[13] Gradny, T., Cadogan, A., McKittrick, T., et al. (1996) Sodium-Selective Electrodes Based on Triester Monoacid Derivatives of p-tert-butylcalix[4]arene. Comparison with Tetraester calyx[4]arene ionophores. Analytica Chimica Acta. 336, 1. http://dx.doi.org/10.1016/S0003-2670(96)00380-7

[14] Hassanzadeh, P., Yaftian, M.R., Bahari, Z. and Matt, D. (2006) A Coated Graphite Thorium-ion Selective Potentiometric Sensor Based on calix[4]arene Bearing Phosphoryl Groups. Journal of the Chinese Chemical Society, 53, 11131118.

[15] O’Conner, K.M., Svehla, G., Hauis, S.J. and Mekervey, M.A. (1992) Calixarene-Based Potentiometric Ion-Selective Electrodes for Silver. Talanta, 39, 1549-1554. http://dx.doi.org/10.1016/0039-9140(92)80140-9

[16] Wilkop, T., Kranse, S., Nabok, A., Ray, A.K. and Yates, R. (2001) The Detection of Organic Polutants in Water with Calixarene Coated Electrodes. Studies in Interface Science, 11, 427-437. http://dx.doi.org/10.1016/S1383-7303(01)80037-5

[17] Kell, D.B., Davery, C.L. (1990) Cass, A.E.G., Ed., Biosensors: A Practical Approach, IRL, Oxford, Chapter 5.

[18] Mourzina, Y., Mai, Th., Poghossian, A., Ermolenko, Yu., et al. (2003) K ${ }^{+}$-Selective Field-Effect Sensors as Transducers for Bioelectronic Applications. Electrochimica Acta, 48, 3333-3339. http://dx.doi.org/10.1016/S0013-4686(03)00402-X

[19] Oelgeklaus, R. and Baltruschat, H. (1997) Detection of Hydrocarbons in Air by Adsorption on Pt-Electrodes Using Continuous Impedance Measurements. Sensors and Actuators B, 42, 31-37. http://dx.doi.org/10.1016/S0925-4005(97)80309-7

[20] Guo Guan, J., Qing Miao, Y. and Zhang, Q. (2004) Impedimetric Biosensors. Biosenscience and Bioengineering, 97, 219-226. http://dx.doi.org/10.1016/S1389-1723(04)70195-4

[21] Ben Ali, M., Homri, T., Korpan, Y., Abdelghani, A., Maaref, M.A., Liu, L., Jaffrezic-Renault, N. and Martelet, C. (2006) Electrical Characterization of Functionalized Platinum Electrodes and ISFET Sensors for Metal Ion Detection. Materials Science and Engineering C, 26, 149-153. http://dx.doi.org/10.1016/j.msec.2005.10.066

[22] Bezzi, N., Merabet, D., Benabdeslem, N. and Arkoub, H. (2001) Caractérisation Physico-Chimique du Minerai de Phosphate de Bled el Hadba Tebessa). Annales de Chime et Sciences des Matériaux, 26, 5-23.

[23] Mlika, R., Ben Ouada, H., Ben Chaabane, R., Gamoudi, M., Guillaud, G., Jaffrezic-Renault, N. and Lamartine, R. (1998) Calixarene Membranes on Semiconductor Substrates for E.I.S. Chemical Sensors. Electrochemica Acta, 43, 841-847.

[24] Ben Ali, M., Bureau, C., Martelet, C., Jaffrezic-Renault, N., Lamartine, R. and Ben Ouada, H. (2000) Comparison of Thiacalix[4]arene Thin Films Behaviour on Different Transducers for Copper Ion Detection. Material Sciences and Engneering C, 7, 83-89.

[25] Scharff, J.P., Mahjoubi, M. and Perrin, R. (1991) Synthesis and Acid-Base Properties of Calix4, Calix6 and Calix8arene p-Sulfonic Acids. New Journal of Chemistry, 15, 883-887.

[26] Matveeva, E.S., Diaz Calleja, R. and Parkhutik, V. (1998) Equivalent Circuit Analysis of the Electrical Properties of Conducting Polymers: Electrical Relaxation Mechanisms in Polyaniline under Dry and Wet Conditions. Journal of Non-Crystalline Solids, 235-237, 772-780. http://dx.doi.org/10.1016/S0022-3093(98)00628-0

[27] McAdams, E.T., Lackermier, A., McLaughlin, J.A., Macken, D. and Jossinet, J. (1995) The Linear and Non-Linear Electrical Properties of the Electrode-Electrolyte Interface. Biosensors and Bioelectronics, 10, 67-74. http://dx.doi.org/10.1016/0956-5663(95)96795-Z

[28] Drelich, J., Millerand, J.D. and Good, R.J. (1996) The Effect of Drop (Bubble) Size on Advancing and Receding Con- 
tact Angles for Heterogeneous and Rough Solid Surfaces as Observed with Sessile-Drop and Captive-Bubble Techniques. Journal of Colloid and Interface Science, 179, 37-50. http://dx.doi.org/10.1006/jcis.1996.0186

[29] Marmur, A. (1994) Thermodynamic Aspects of Contact Angle Hysteresis. Advances in Colloids and Interface Science, 50, 121-141. http://dx.doi.org/10.1016/0001-8686(94)80028-6

[30] Van Der Wal, P.D., Sudholter, E.J.R., Boukamp, B.A., et al. (1991) Impedance Spectroscopy and Surface Study of Potassium-Selective Silicone Rubber Membranes. Journal of Electroanaytical Chemistry, 317, 153-168. http://dx.doi.org/10.1016/0022-0728(91)85010-M

[31] Boukamp, B.A. (1993) Manual AC-Immittance Data Analysis System Equivalent Circuit, Version 4.5, University of Twente, Twente.

[32] Armstrong, R.D., Covington, A.K. and Evans, G.P. (1983) Mechanistic Studies of the Valinomycin-Based PotassiumSelective Electrode Using AC Impedance Methods. Journal of Electroanaytical Chemistry, 159, 33-40. http://dx.doi.org/10.1016/S0022-0728(83)80312-X

[33] Antropov (1979) Electrochimie Théorique, Edition Mir, Mouscou.

[34] Sakly, H., Mlika, R., Chaabane, H., Beji, L. and Ben Ouada, H. (2006) Anodically Oxidized Porous Silicon as a Substrate for EIS Sensors. Materials Science and Engineering C, 26, 232-235.

http://dx.doi.org/10.1016/j.msec.2005.10.057 